\title{
CONSTRUÇÃO DE UM CALORÍMETRO ISOTÉRMICO DIFERENCIAL DE ALTA SENSIBILIDADE E BAIXO CUSTO
}

\author{
Rafael Bergamo Trinca*, Carlos Eduardo Perles e Pedro Luiz Onófrio Volpe \\ Departamento de Físico-Química, Instituto de Química, Universidade Estadual de Campinas, CP 6154,13083-970 Campinas - SP, \\ Brasil
}

Recebido em 7/10/08; aceito em 11/2/09; publicado na web em 3/7/09

\begin{abstract}
CONSTRUCTION OF A DIFFERENTIAL ISOTHERMAL CALORIMETER OF HIGH SENSITIVITY AND LOW COST. The high cost of sensitivity commercial calorimeters may represent an obstacle for many calorimetric research groups. This work describes the construction and calibration of a batch differential heat conduction calorimeter with sample cells volumes of about $400 \mu \mathrm{L}$. The calorimeter was built using two small high sensibility square Peltier thermoelectric sensors and the total cost was estimated to be about US\$ 500. The calorimeter was used to study the excess enthalpy of solution of binary mixtures of liquids, as a function of composition, for the following binary systems of solvents: water + 1,4-dioxane or + dimethylsulfoxide at 298,2 $\pm 0,5 \mathrm{~K}$.
\end{abstract}

Keywords: calorimeter; excess enthalpy of solution; binary mixture.

\section{INTRODUÇÃO}

A calorimetria é uma técnica físico-química capaz de medir o efeito térmico e, consequentemente, a variação de entalpia associada a processos químicos, físicos ou bioquímicos que ocorrem num sistema de interesse. ${ }^{1}$

Os modernos calorímetros isotérmicos diferenciais de condução de calor utilizam como sensores térmicos um dispositivo termoelétrico conhecido como Peltier ou termopilha. Estes componentes eletrônicos, que foram desenvolvidos para aplicações aeroespaciais e militares, são constituídos por pares de semicondutores (telureto de bismuto dopado, tipo $\mathrm{N}$ e P) combinados em um módulo, onde são conectados eletricamente em série e termicamente em paralelo. ${ }^{2}$ A termopilha é sensível a diferenças de temperatura da ordem de $10^{-4}{ }^{\circ} \mathrm{C}$ entre suas faces, gerando uma diferença de potencial entre os terminais do dispositivo. ${ }^{2}$

Nos calorímetros isotérmicos diferenciais de condução de calor, também chamados de microcalorímetros, os dispositivos Peltier localizam-se na superfície externa da célula calorimétrica, formando uma ponte para o escoamento do calor entre a célula de reação e o seu arredor, normalmente um bloco metálico de alta capacidade calorífica, mantido à temperatura constante. $\mathrm{O}$ termo microcalorimetria surgiu em função da alta sensibilidade do sensor Peltier, permitindo que quantidades de fluxo de calor na escala de microwatts $(\mu \mathrm{W})$ fossem detectadas. Desta forma, o prefixo micro refere à alta sensibilidade dos equipamentos que utilizam esse tipo de sensor. ${ }^{3}$

Entre as inúmeras aplicações de um calorímetro isotérmico diferencial de condução de calor, destaca-se sua aplicação na determinação da entalpia molar em excesso $\left(\Delta H_{m}^{E}\right)$ de misturas binárias de líquidos, o que é possível devido a sua alta sensibilidade.

Scatchard ${ }^{4,5}$ definiu uma função de excesso como a diferença entre o valor de uma função termodinâmica de solução em um estado qualquer e o valor dessa para uma solução ideal (ou solução diluída ideal), nas mesmas condições de temperatura, pressão e composição. Portanto, por definição, o valor da grandeza termodinâmica $\Delta H_{m}^{E}$ para uma solução ideal é zero.

Para a formação de uma solução binária ideal entre um solvente A e um solvente B, é necessário que as interações A-A, B-B e A-B

*e-mail: rafaeltrinca@gmail.com sejam iguais e, dessa forma, a entalpia de mistura de A com B será igual a zero. Entretanto, as soluções reais são constituídas por moléculas cujas interações do tipo A-A, B-B e A-B são diferentes. Assim, a entalpia de excesso está relacionada com a entalpia de mistura, pois os valores ideais são nulos.

Propriedades de excesso são grandezas físico-químicas que representam o excesso (positivo ou negativo) de uma função termodinâmica de solução em relação a uma solução ideal. ${ }^{6}$ As funções de excesso constituem um caminho usual para expressar a extensão com a qual uma solução real desvia da idealidade. ${ }^{7}$

A $\Delta H_{m}^{E}$, assim como o volume molar em excesso (outra propriedade de excesso bastante explorada) de misturas de solventes, pode ser interpretada como o resultado de fatores estruturais, estéricos e/ou de diferenças na natureza das interações químicas entre as espécies puras e a mistura. Dessa forma, o estudo da entalpia de misturas binárias de líquidos permite investigar a ocorrência e a natureza das interações químicas a partir das variações das energias de interação inter e intramoleculares, entre as espécies puras e a mistura.

No entanto, os elevados custos da aquisição e manutenção de um calorímetro diferencial isotérmico são, muitas vezes, um obstáculo para muitos grupos de pesquisa.

Diante dessa situação, o objetivo deste trabalho é descrever a construção, calibração e aplicação de um calorímetro que apresenta não apenas um baixo custo de montagem (aproximadamente US\$500), como também alta sensibilidade e, consequentemente, a necessidade de pequenos volumes de solventes. A utilização de pequenas quantidades de solventes é uma vantagem não apenas pela redução de custo da pesquisa, mas, também, pela redução na quantidade de resíduos gerados.

Dessa forma, propomos a construção deste calorímetro como uma solução de baixo custo e alta confiabilidade, para utilização tanto em pesquisa acadêmica como didaticamente.

\section{PARTE EXPERIMENTAL}

\section{Montagem e teste do calorímetro}

O calorímetro é formado por duas células cilíndricas de $1,5 \mathrm{~cm}$ de altura e $0,6 \mathrm{~cm}$ de diâmetro confeccionadas em cobre e revestidas eletroquimicamente com ouro, tendo cada célula um volume inter- 
no de $380 \mu \mathrm{L}$. As células foram soldadas sobre uma das faces das termopilhas de 0,6 x 0,6 cm (Melcor). Devido à baixa temperatura de fusão dos elementos semicondutores constituintes da termopilha, a soldagem foi feita utilizando-se como solda o metal de Wood, o qual é uma liga eutética com a seguinte composição: $50 \%$ Bi, $25 \%$ $\mathrm{Pb}, 12,5 \% \mathrm{Sn}$ e $12,5 \% \mathrm{Cd}$, com ponto de fusão $68^{\circ} \mathrm{C} .{ }^{8}$

A outra face das termopilhas foi soldada sobre um disco metálico de $0,3 \mathrm{~cm}$ de altura e $4,0 \mathrm{~cm}$ de diâmetro, também revestido com ouro (Figura 1). A seguir, o disco metálico foi conectado, utilizando pasta térmica ( $\mathrm{ZnO}$ pulverizado disperso em óleo de silicone) a um bloco trocador de calor de alumínio de 3,0 cm de altura e 4,0 cm de diâmetro.

A dissipação do calor oriundo da célula de reação foi maximizada com a inserção de outro trocador de calor, de alta área superficial, também aderido com pasta térmica na extremidade inferior do bloco trocador de calor. Esse trocador de calor foi adaptado a partir de um dissipador utilizado em processadores para computador. Um esquema detalhado pode ser observado na Figura 1.

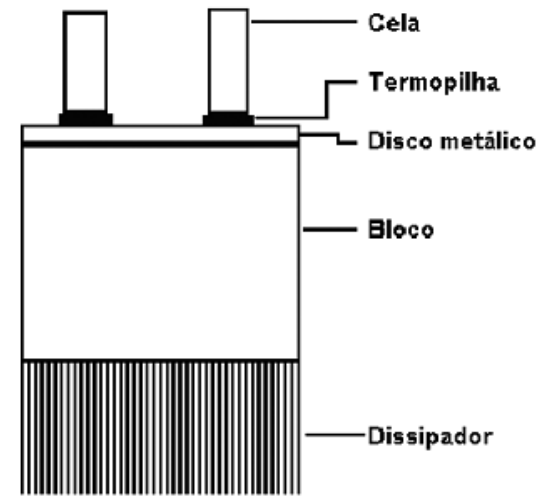

Figura 1. Representação esquemática do calorímetro

As termopilhas foram conectadas eletricamente em série, com as duas faces equivalentes voltadas para o mesmo lado e com a ligação fechando uma junção do tipo P-N, de forma que a direção do fluxo de calor sobre suas superfícies (da amostra para a termopilha ou da termopilha para a amostra - exotérmico e endotérmico, respectivamente) irá gerar uma diferença de potencial, positiva ou negativa. Para maiores detalhes sobre o funcionamento das termopilhas, recomenda-se a leitura da ref. 2.

Embora as termopilhas sejam detectores de alta sensibilidade, o pequeno volume de solução para o qual o calorímetro foi projetado $\mathrm{e}$, consequentemente, a baixa magnitude do sinal de potencial tornou necessária a amplificação do sinal oriundo das termopilhas. Um teste realizado com uma mistura binária de etanol em água (1:2) gerou, apenas $20 \mathrm{mV}$ no pico de sinal. Diante desse resultado preliminar, construiu-se um amplificador de tensão utilizando-se o amplificador operacional LM741. O fator de amplificação foi de, aproximadamente, 100 vezes.

O sinal amplificado foi coletado por um multímetro digital (Minipa ET-2231) conectado a um computador via RS-232. Os dados foram registrados em formato .txt.

O bloco trocador de calor foi fixado a uma estrutura de acrílico responsável pela sustentação de todo o sistema calorimétrico no interior de uma jaqueta de vidro. Na parte superior dessa estrutura há dois furos, alinhados com as células de reação, para suporte da seringa de adição (Hamilton gas-tight, $250 \mu \mathrm{L}$ ) (Figura 2).

A jaqueta de vidro permite a circulação de água proveniente de um banho termostático (Microquímica MQBCT99-20). Após a montagem, este conjunto foi acondicionado no interior de uma caixa de isopor com paredes de $5 \mathrm{~cm}$ de espessura.
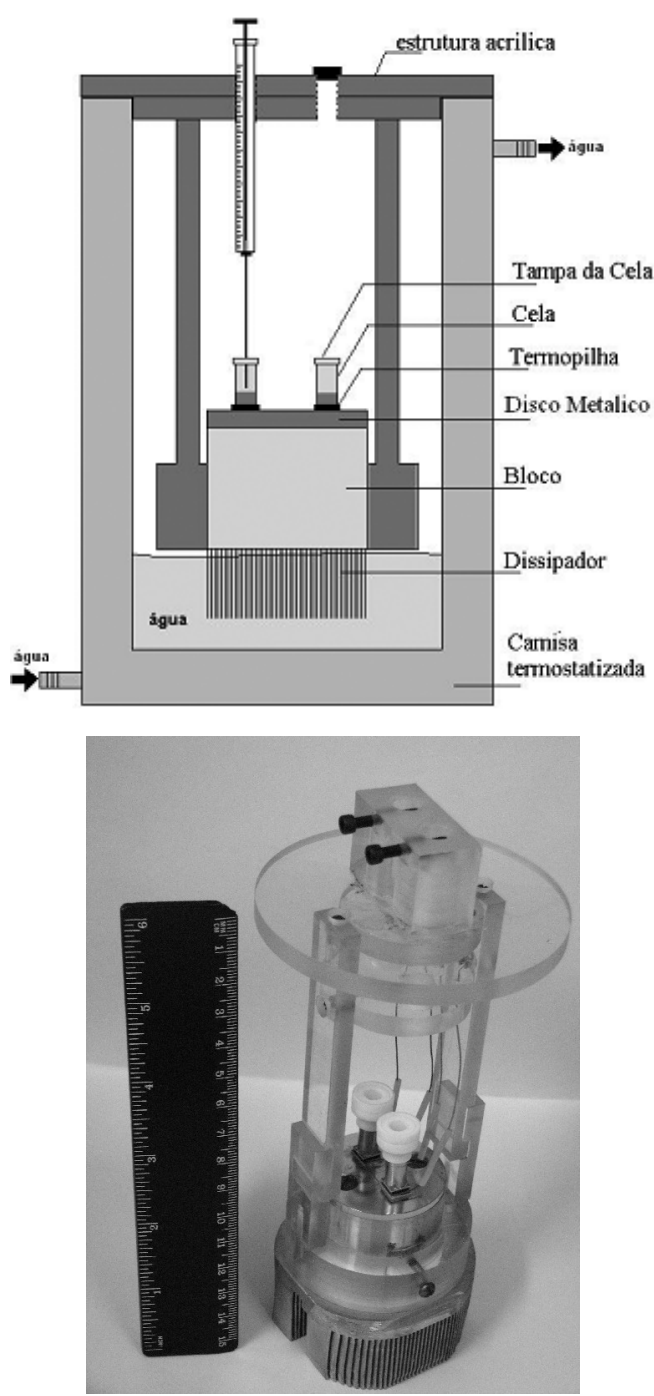

Figura 2. a) Representação esquemática detalhada do calorímetro; b) foto do calorímetro

Após a montagem, foram realizados testes preliminares com o objetivo de verificar a resposta do calorímetro e a necessidade de ajustes.

Para esses testes iniciais foram feitas injeções de $100 \mu \mathrm{L}$ de etanol em $200 \mu \mathrm{L}$ de água bidestilada, contida na célula de amostra. A temperatura do sistema foi mantida constante em 298,2 \pm 0,5 K. A aquisição dos dados foi realizada em intervalos de $1 \mathrm{~s}$. O sistema etanol + água foi escolhido por ser bastante exotérmico.

Antes das adições do conteúdo da seringa na célula de amostra, tomou-se sempre o cuidado de acompanhar a variação da linha base por, no mínimo, $5 \mathrm{~min}$, para certificação de que o sistema atingiu o equilíbrio térmico.

Como procedimento padrão, definiu-se como 500 s o intervalo de tempo para a aquisição de dados, tempo suficiente para que o efeito térmico gerado pela mistura entre os solventes cesse e todo calor escoe para as vizinhanças, de forma que a curva potencial vs. tempo $(\mathrm{V}-\mathrm{t})$ retorne para a linha base.

Para todos os sistemas estudados, a aquisição de dados foi iniciada $10 \mathrm{~s}$ antes da injeção do solvente de interesse na célula de reação, possibilitando a obtenção de uma linha base. Os dados calorimétricos (potencial em função do tempo) foram coletados em formato digital e tratados num programa gráfico $\left(\right.$ Origin $^{\circledR}$ ), onde foram construídas as curvas $\mathrm{V}$-t, conforme exemplo apresentado na Figura 3. 
A área (S) sob a curva V-t, apresentada na Figura 3, obtida através de integração, é diretamente proporcional ao calor produzido pela mistura dos solventes (água/etanol).

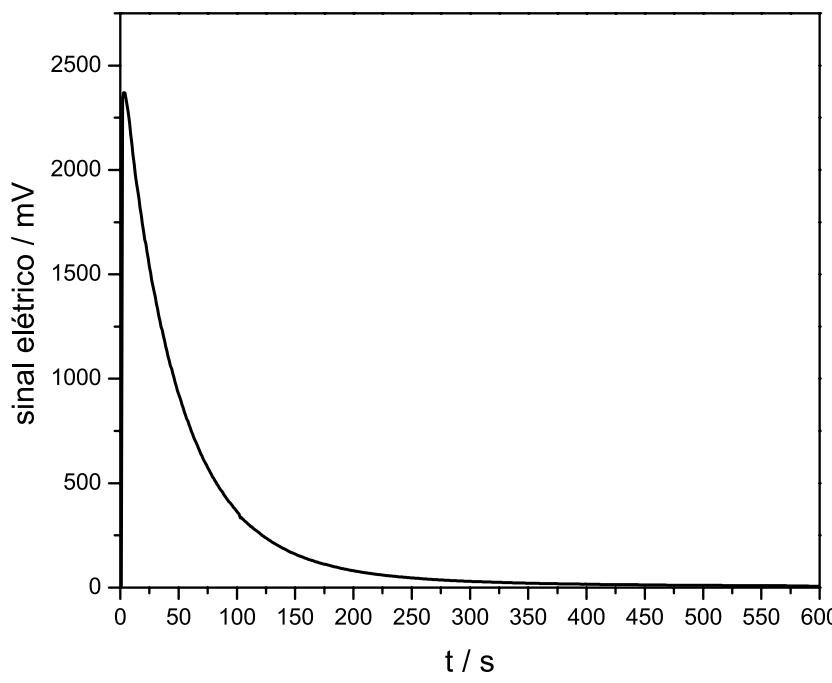

Figura 3. Curva de potencial vs. tempo $(V-t)$ para o sistema teste etanol + água $(1: 2)$

\section{Calibração do calorímetro}

Após as etapas de montagem e verificação da resposta do calorímetro, este foi calibrado utilizando-se um método químico padrão.

Para a calibração química, utilizou-se o método padrão que consiste na $\Delta H^{E}$ do sistema binário água +2 -propanol, em diferentes frações molares. Os valores $\Delta H_{m}^{E}$ para essas misturas e suas respectivas frações molares $\left(x_{H_{0}}\right)$ encontram-se na Tabela $1 .{ }^{9} \mathrm{O}$ método utilizado na calibração foi uma adaptação dos estudos apresentados por Olofsson et al.. ${ }^{10}$

Para essa calibração, utilizou-se 2-propanol anidro (99,5\%, Sigma-Aldrich) e água bidestilada. Para cada composição do sistema água +2 -propanol contida na Tabela 1 , foram realizadas medidas em triplicata.

Tabela 1. Valores de $\Delta H_{m}^{E}$ para o sistema binário água/ 2-propanol a $298,15 \mathrm{~K}$, em função da fração molar da água $\left(x_{H_{0}}\right)^{9}$

\begin{tabular}{lc}
\hline$x_{H_{2} 0}$ & $\Delta H_{m}^{E} / \mathrm{J}$ \\
\hline 0,9725 & $-326,4$ \\
0,8910 & $-652,3$ \\
0,5908 & $-108,4$ \\
0,4475 & 95,4 \\
0,3471 & 204,2 \\
\hline
\end{tabular}

A área (S) da curva $V$ - $t$, obtida para cada experimento com os diferentes valores de $x_{H, 0}$, foi corrigida considerando $1 \mathrm{~mol} \mathrm{de} \mathrm{mis-}$ tura, ou seja:

$\mathrm{S}_{\mathrm{m}}=\mathrm{S} / \mathrm{n}$

onde: $\mathrm{S}_{\mathrm{m}}$ é a área da curva por mol de solução, em $\mathrm{mV} \mathrm{s} \mathrm{mol}{ }^{-1} \mathrm{e}, \mathrm{n}$ o número total de mols na solução ou,

$\mathrm{n}=\mathrm{n}_{\mathrm{A}}+\mathrm{n}_{\mathrm{B}}$ sendo que:

$\mathrm{n}_{\mathrm{x}}=\mathrm{V}_{\mathrm{x}} \cdot \rho_{\mathrm{x}} / \mathrm{M}_{\mathrm{x}}$

onde: $\mathrm{n}_{\mathrm{x}} \mathrm{V}_{\mathrm{x}}, \rho_{\mathrm{x}}$ e $\mathrm{M}_{\mathrm{x}}$ são, respectivamente, o número de mols, volume $\left(\mathrm{cm}^{3}\right)$, densidade $\left(\mathrm{g} \mathrm{cm}^{-3}\right)$ e a massa molar $\left(\mathrm{g} \mathrm{mol}^{-1}\right)$ do solvente $\mathrm{x}$.

Relacionando-se os valores tabelados de $\Delta H_{m}^{E}$ do sistema água + 2-propanol ${ }^{9}$ à 298,15 K, Tabela 1 , com os respectivos valores de $\mathrm{S}_{\mathrm{m}}$ obteve-se a relação apresentada na Figura 4. A regressão linear desta curva permitiu a obtenção de uma equação geral para o calorímetro (Equação 4), na temperatura de 298,2 \pm 0,5 K. Essa equação relaciona a área obtida $\mathrm{S}_{\mathrm{m}}\left(\mathrm{mV} \mathrm{s} \mathrm{mol}^{-1}\right)$ com a $\Delta H_{m}^{E}(\mathrm{~J})$ do processo em análise.

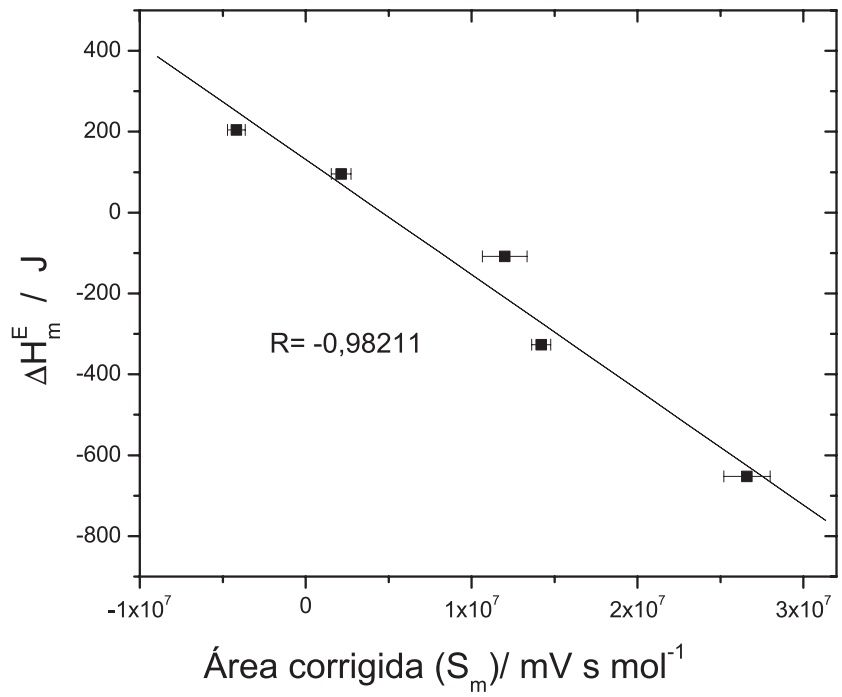

Figura 4. Valores da literatura para entalpia molar em excesso $\left(\Delta H_{m}^{E}\right)$ de mistura água/2-propanol em função da área corrigida $S_{m}$, utilizados para a calibração do calorímetro a $288,2 \pm 0,5 \mathrm{~K}$

Os parâmetros do ajuste linear estão expressos na Equação 4,

$\Delta H_{m}^{E}=131-2,8 \cdot 10^{-5} \mathrm{~S}_{\mathrm{m}}$

\section{Determinação da entalpia molar de excesso em sistemas líquidos binários}

Após a calibração, dois sistemas líquidos binários foram escolhidos para a determinação da $\Delta H_{m}^{E}$ em função da fração molar de um dos componentes. Os sistemas escolhidos foram: água + 1,4-dioxano e água + dimetilsulfóxido. A escolha desses sistemas tem como objetivo complementar estudos anteriores de volume molar em excesso $\left(V_{m}^{E}\right)$ desses dois sistemas, realizados recentemente em nosso grupo de pesquisa. ${ }^{11}$

Ambos os sistemas foram estudados a 298,2 $\pm 0,5 \mathrm{~K}$.

As medidas calorimétricas foram realizadas em diferentes frações molares, cobrindo toda a faixa de solubilidade entre os solventes, sendo que para cada adição a alíquota de maior volume era colocada na célula de reação e a alíquota de menor volume adicionada com a microsseringa.

Obteve-se, desta maneira, as curvas V-t para cada fração molar. Os valores $\mathrm{S}_{\mathrm{m}}$ obtidos foram aplicados na equação geral do calorímetro, Equação 4, para se obter os valores da $\Delta H_{m}^{E}$ em função das frações molares $\left(x_{H, 0}\right)$. As Figuras 5 e 6 mostram, respectivamente, o comportamento da $\Delta H_{m}^{E}$ dos sistemas água $+1,4$-dioxano e água + dimetilsulfóxido em função da $x_{H, 0}$ a 298,2 \pm 0,5 K, em comparação com os dados da literatura. 


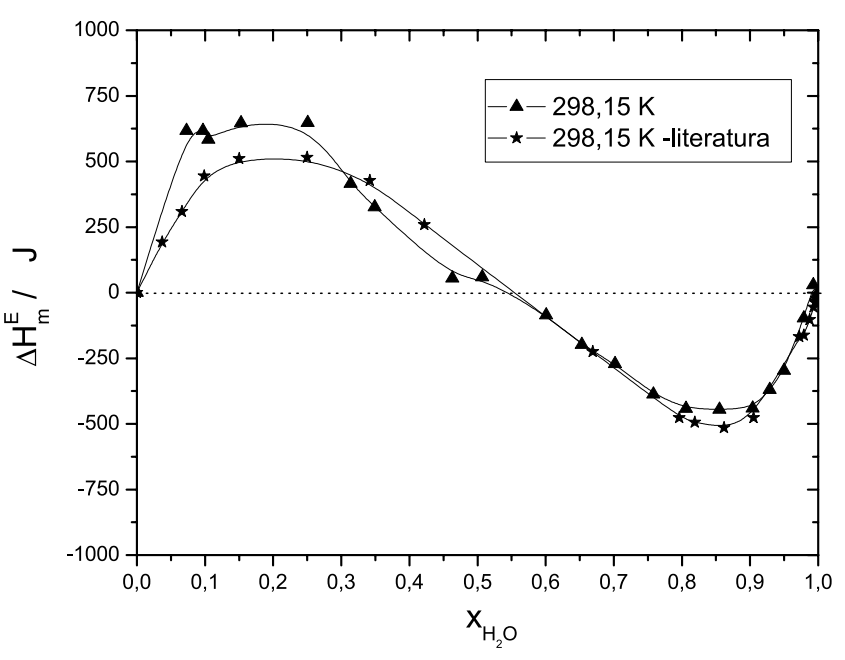

Figura 5. Entalpia molar em excesso $\left(\Delta H_{m}^{E}\right)$ em função da fração molar da água $\left(x_{H_{0}}\right)$ para o sistema água/1,4-dioxano, obtido experimentalmente e da literatura na temperatura de $298,2 \pm 0,5 \mathrm{~K}$

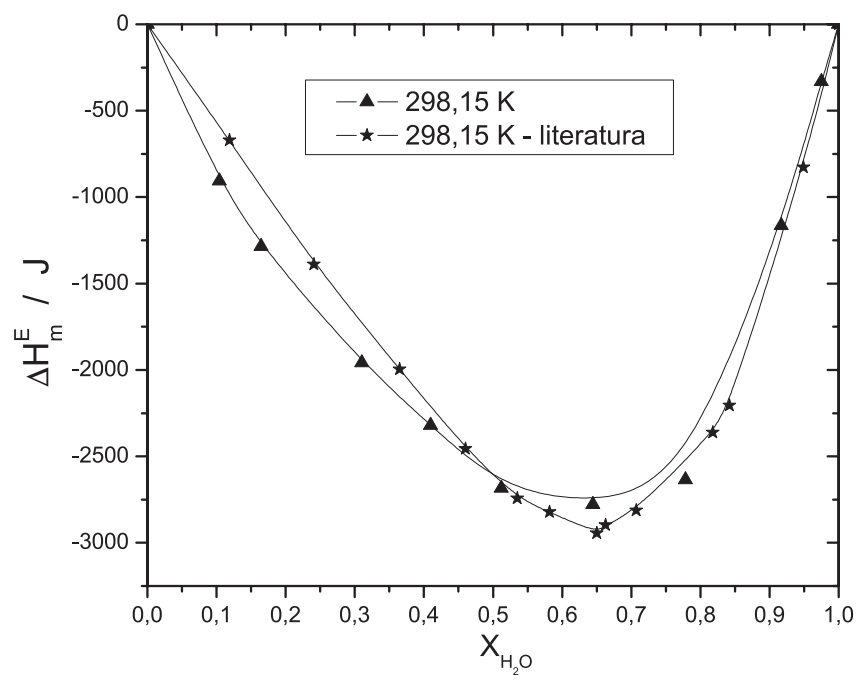

Figura 6. Entalpia molar em excesso $\left(\Delta H_{m}^{E}\right)$ em função da fração molar de água $\left(x_{H O}\right)$ para o sistema água/dimetilsulfóxido, obtido experimentalmente e da literatura na temperatura de 298,2 $\pm 0,5 \mathrm{~K}$

\section{RESULTADOS E DISCUSSÃO}

Com base nos valores de referência encontrados na literatura para o sistema líquido binário água + 2-propanol, ${ }^{9}$ utilizados na calibração, concluímos que o calorímetro construído apresenta alta sensibilidade, reprodutibilidade e confiabilidade. Os resultados de $\Delta H_{m}^{E}$ obtido para os sistemas água + 1,4-dioxano e água + dimetilsulfóxido, mostrados nas Figuras 5 e 6, estão em boa concordância com os valores apresentados na literatura. ${ }^{9}$
No decorrer da construção e uso do calorímetro, constatamos que o projeto poderá ser aperfeiçoado, sendo necessário para isto, um maior distanciamento entre as células de amostra e de referência o que, talvez, possa ser conseguido utilizando um bloco trocador de calor na forma de U. Na construção do calorímetro, todos os cuidados foram tomados para minimizar ao máximo o efeito da flutuação da temperatura nos arredores deste, utilizando uma configuração diferencial na montagem das termopilhas. Entretanto, devido à alta sensibilidade do equipamento, se faz necessário também o uso de um banho termostático com controle mais eficiente de temperatura, pois observamos que oscilações da temperatura da água circulante na camisa, da ordem de $\pm 0,5^{\circ} \mathrm{C}$, gera ruído no sinal térmico podendo, dependendo da magnitude do sinal térmico, comprometer os resultados.

\section{MATERIAL SUPLEMENTAR}

O material suplementar encontra-se disponível gratuitamente, na forma de arquivo PDF, no endereço: http://quimicanova.sbq. org.br. Conta com figuras ilustrativas do elemento peltier (Figura $1 \mathrm{~S}$ ), esquemas da construção do amplificador de sinal (Figura 2S) e desenhos técnicos detalhados da construção do calorímetro (Figura 3S).

\section{AGRADECIMENTOS}

À FAPESP - Fundação de Amparo à Pesquisa do Estado de São Paulo; ao CNPq - Conselho Nacional de Desenvolvimento Científico e Tecnológico e ao Prof. F. Y. Fujiwara pelos comentários críticos.

\section{REFERÊNCIAS}

1. Miles, R. J.; Beezer, A. E.; Perry, B. F.; Thermal and Energetic Studies of Cellular Biological Systems, IOP Publishing LTD: Bristol, 1987, p. 106.

2. Volpe, P. L. O.; Quim. Nova 1993, 16, 49.

3. Perles, C. E.; Dissertação de Mestrado, Universidade Estadual de Campinas, Brasil, 2006.

4. Scatchard, G.; Chem. Rev. 1931, 8, 321.

5. Scatchard, G.; Hamer, W. J.; J. Am. Chem. Soc. 1935, 57, 1805.

6. Guggenheim, E. A.; Thermodynamics, $5^{\text {th }}$ ed., Publishing Company: North-Holland, 1967.

7. Rowlinson, J. S.; Swinton, F. J.; Liquid and Liquid Mixtures, $3^{\text {rd }}$ ed., Butterworths: London, 1982.

8. Sedlacek, V.; Non-Ferrous Metals and Alloys, Elsevier: New York, 1986.

9. Christensen, J. J.; Handbook of Heats of Mixing, John Wiley \& Sons: USA, 1982, p. 1414, 1456, 1468.

10. Olofsson, G.; Berling, D.; Markova, N.; Molund, M.; Thermochim. Acta 2000, 347, 31.

11. Tôrres, R. B.; Marchiore, A. C. M.; Volpe, P. L. O.; J. Chem. Thermodyn. 2006, 38, 526. 


\section{CONSTRUÇÃO DE UM CALORÍMETRO ISOTÉRMICO DIFERENCIAL DE ALTA SENSIBILIDADE E BAIXO} CUSTO

Rafael Bergamo Trinca*, Carlos Eduardo Perles e Pedro Luiz Onófrio Volpe

Departamento de Físico-Química, Instituto de Química, Universidade Estadual de Campinas, CP 6154,13083-970 Campinas - SP, Brasil

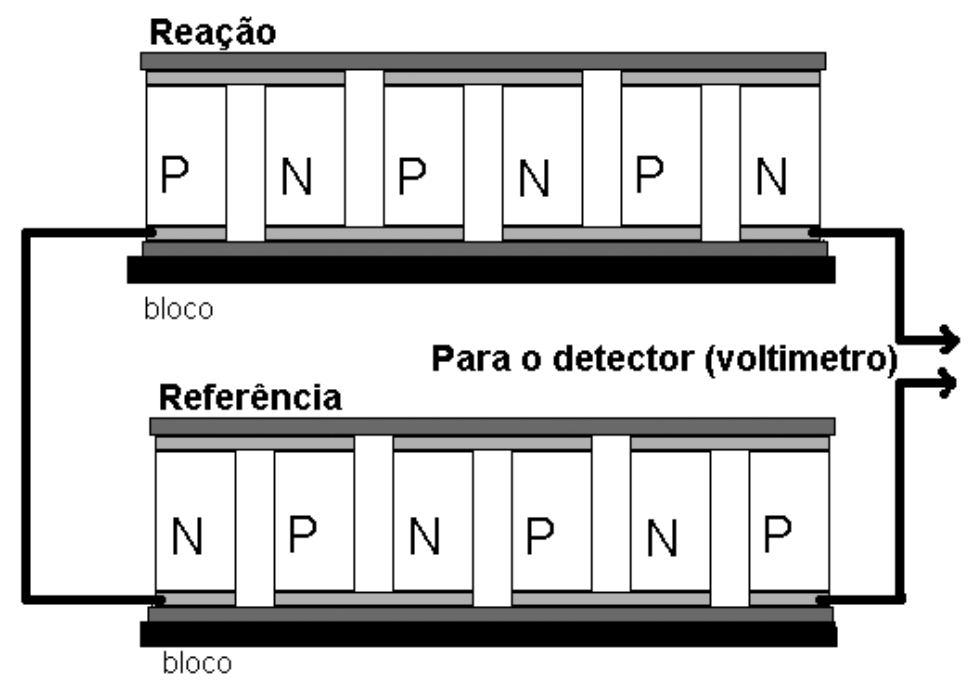

Figura 1S. Representação esquemática da conexão elétrica das termopilhas no sistema diferencial

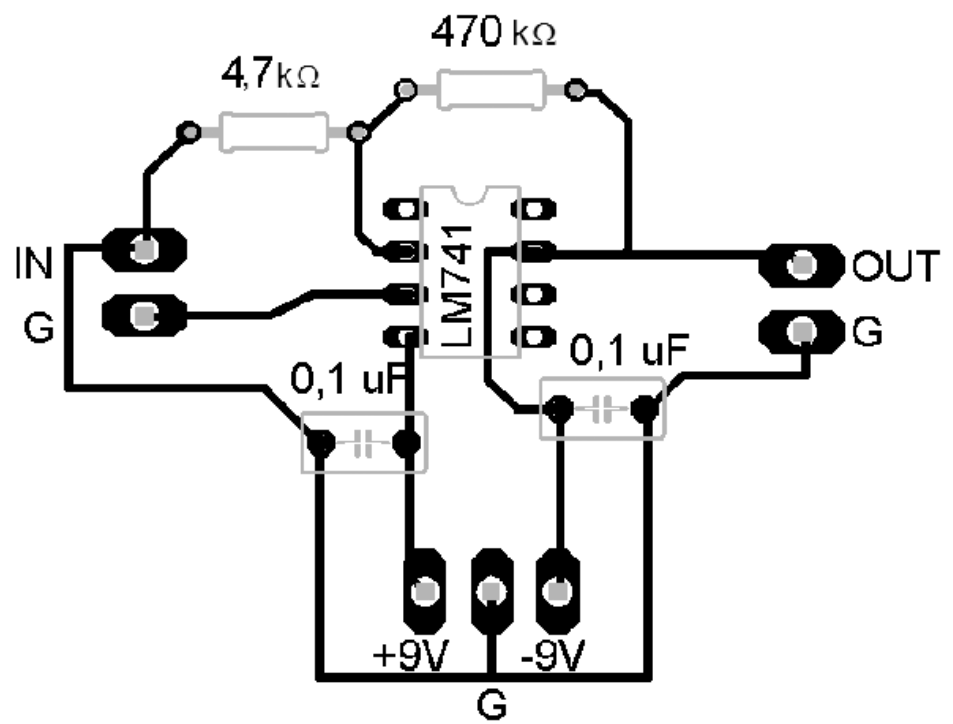

Figura 2S. Esquema do amplificador de sinal 
a)
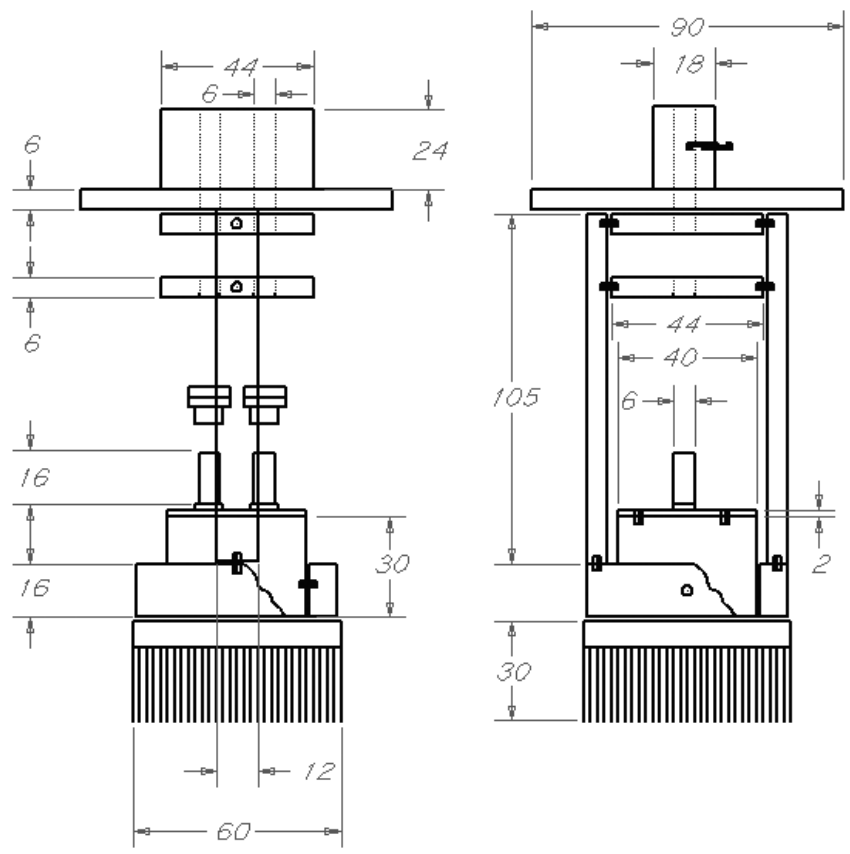

b)
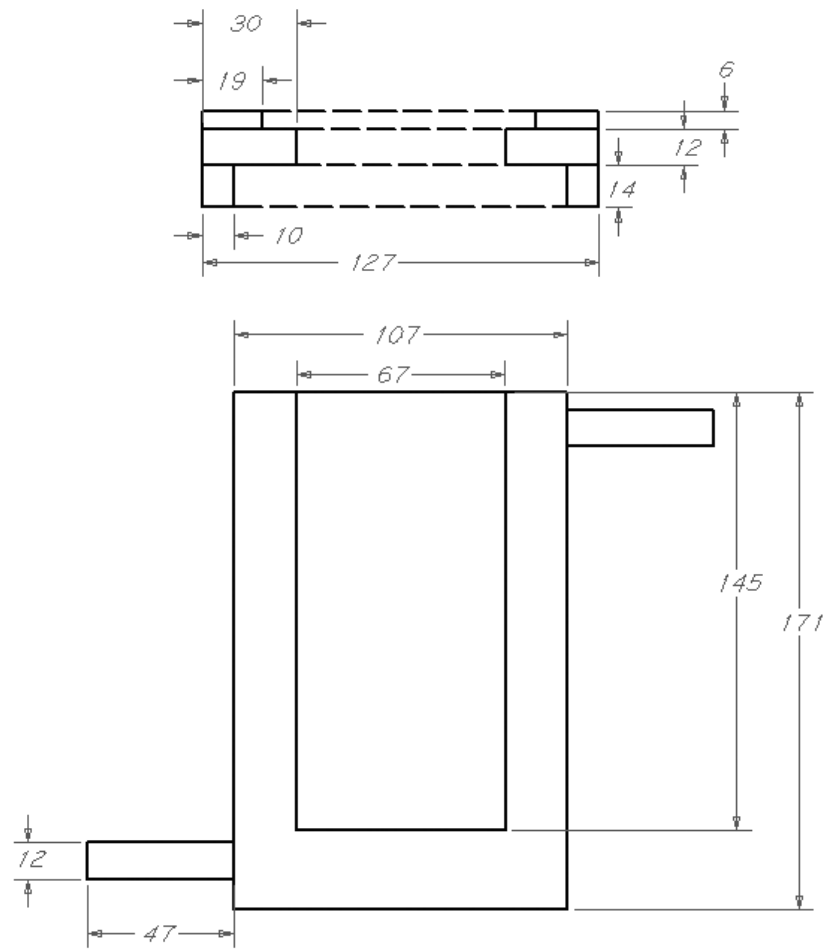